\title{
Laboratory Evaluation of the Stiffness Modulus of a Modified Bituminous Concrete with PR PLAST Sahara
}

\author{
Imane Harizi ${ }^{1}$, Meriem Morsli ${ }^{2}$ and Mahmoud Bensaibi ${ }^{1}$ \\ 1. Department of Civil Engineering, University of Blida, Blida 09000, Algeria \\ 2. Department of Civil Engineering, Ecole Nationale Polytechnique, Algiers 16000, Algeria
}

\begin{abstract}
Uneven roads surface can be observed on bituminous pavements. This is due to moving loads and climate conditions. If the observed deformations exceed the elastic limit, important damages can occur, so new materials are used to improve the stiffness modulus of bituminous mixtures. To achieve this, a modified bituminous concrete by addition of the PR PLAST Sahara (produced by PR industries and PLAST for Plastic) mainly used in arid region has been studied. The use of this additive at various percentages 0.1 , 0.3, 0.6 and 0.9 by weight of bituminous concrete has been investigated to determine its stiffness modulus. An experimental design using the Taguchi tables has been elaborated to reduce the number of tests. Marshall and NAT (Nottingham asphalt tester) tests have been carried out, and a mathematical model of the stiffness modulus has been proposed.
\end{abstract}

Key words: Modified bituminous concrete, PR PLAST Sahara, Taguchi method, stiffness modulus, Marshall test, Nottingham asphalt tester.

\section{Introduction}

Laboratory tests on bituminous materials are commonly used to improve their characteristics $[1,2]$. For many decades, conventional bituminous materials have been used satisfactorily in most roadway applications. However, due to traffic loading and environmental factors such as temperature, air, and water, the durability of the asphalt concrete mixtures can be greatly affected [3,4]. Improving bituminous mixture properties by using several additives to enhance roadway performance will be of great importance in the field of transportation research [5]. The use of artificial polymers as additives, by chemical or physical combination, has led to a better performance of conservative asphalts. The thermoplastic nature of these binders has displayed the aptitude to combine property of softness, strong point and linkage to increase highways service live [6].

Corresponding author: Mahmoud Bensaibi, professor, research fields: seismic vulnerability of existing structures, seismic vulnerability of lifelines, seismic scenarios, seismic risk management and torsion effect on asymmetric buildings. E-mail: bensaibim@yahoo.co.uk.
Improved properties also include greater resistance to aging and stability at high temperatures. Polymers, which are the most commonly used additives in binder modification, can be classified into four main categories, namely elastomers, plastomers, fibers and coatings. To achieve the goal of improving bitumen properties, a selected polymer should create a secondary network or new balance system within bitumen by molecular interactions or by chemical reaction with the binder [7]. The formation of a functional modified bitumen system is based on the fines dispersion of polymer in bitumen for which the chemical composition of bitumen is important [8]. Among polymers, the elastomer SBS (styrene-butadiene-styrene) block copolymer is the most widely used. It increases the elasticity of bitumen. It has been identified that SBS can obviously improve the mechanical properties of mixtures such as aging [9, 10], permanent deformation [11-17], low temperature cracking [18-20] and moisture damage resistance [21-23].

The semi-crystalline copolymer, EVA (ethylene vinyl acetate) is classified as plastomer that modifies 
bitumen by forming a tough, rigid, three-dimensional network to resist deformation and is one of the main plastomers used in road construction in order to improve both the workability of the asphalt during construction and its deformation resistance [23-25].

Fibers can also be used for modification of bitumen. It should be noted that different types of fibers (polyester, polyacrylonitrile, lignin, asbestos, etc.) increase rutting resistance of the bitumen [26-28].

Better rutting and cracking resistances have been obtained by addition of bentonite clay and organically modified bentonite clay [29] and nanoclay [30]. Montmorillonite and organically modified montmorillonite have also enhanced the rutting resistance of the bitumen [31].

Many studies about modified bitumen properties and their effects have been reported in the literature. Among them the TEGPB (triethylene glycol based synthetic polyboron) modified bitumen was investigated. It was reported that the effect of TEGPB is to provide additional resistance for roadways to resist pavement distresses and it was recommended to use in hot climate regions [32]. Research was conducted to investigate the effect of mixing process on PP (polypropylene) modified bitumen mixed with well graded aggregate to form modified bituminous concrete mix [33]. The influence of HDPE (high density polyethylene) on mechanical properties was also investigated [34]. The effects of waste polymer modifier were evaluated, too [35-45]. Development of models to predict asphalt pavements properties and behaviour was also performed [46-50].

The aim of this study is to determine the stiffness modulus of a bituminous mixture with PR PLAST Sahara as an additive using the Nottingham asphalt tester. The physical and mechanical properties of polymer modified binder-aggregate mixes were evaluated with conventional tests such as Marshall stability. In addition, Taguchi method [51-56] was used in order to reduce the number of samples and to develop a model for the stiffness modulus.

\section{Taguchi Method and Research Model}

The Taguchi method consists of experimental planning with the objective of acquiring data in a controlled way to obtain information about the behaviour of a given process. The main advantage of Taguchi method over the conventional experimental design method is that it minimizes the cost and the time needed.

\subsection{Adjustment of the Linear Model}

The following development is given for clarity of the procedure. It is well known in statistical domain. A linear model is an equation where a response $y$ is function of $k$ variables $x_{i}$, it can be written as follows:

$$
y=c+\sum_{i=1}^{k} a_{i} x_{i}+e
$$

where, $c$ and $a_{i}$ are coefficients to be estimated and $e$ is a random error. The estimated response $\hat{y}$ is calculated so that the residue $r$ is minimal:

$$
r=y-\hat{y}
$$

The estimated coefficients are determined by the least square method (sketched in Fig. 1).

In Fig. 1, $X$ is the test matrix in which each line $i$ contains the $k$ variables of experiment $i, A$ is a vector which contains the coefficients to be determined, $Y$ is the responses vector and $E$ is the residues vector.

Assuming that $Y$ follows a Gaussian distribution, lets $\hat{Y}$ be the estimated response vector and $\hat{A}$ be the estimated coefficient vector, so it can be written:

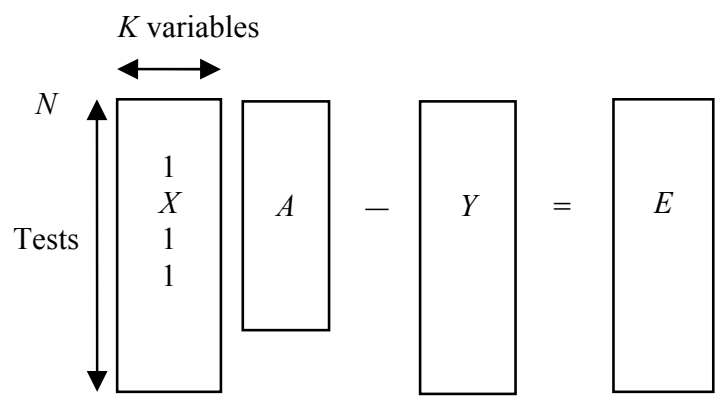

Fig. 1 Matrix representation of the linear model [52]. 


$$
\hat{Y}=X \hat{A}
$$

Thus,

$$
E=Y-X \hat{A}
$$

The minimisation of the sum of the square of Eq. (4) let to obtain Eq. (5):

$$
\frac{\partial}{\partial A} E^{t} E=0=\frac{\partial}{\partial A}\left[(Y-X \hat{A})^{t}(Y-X \hat{A})\right]
$$

Development of Eq. (5) allows to write:

$$
\partial\left(E^{t} E\right)=2(Y-X \hat{A})^{t} \partial(Y-X \hat{A})
$$

then

$$
X^{t} Y-X^{t} X \hat{A}=0
$$

so the obtained estimated coefficient vector is:

$$
\hat{A}=\left(X^{t} X\right)^{-1} X^{t} Y
$$

It can be shown, using covariance matrices that a best estimation is obtained for a matrix $\left(X^{t} X\right)^{-1}$ with small diagonal terms and null non diagonal terms [52]. This rule is the base of experimental design [52].

\subsection{Taguchi's Table}

In order to obtain more robust processes in the varying environmental conditions and the variability in components, after bringing the mean performance value to the target value, Genichi Taguchi reported that experimental designs could be utilized in making the variability around this target a minimum. According to Taguchi, the performance of a product may be affected by: (1) environmental conditions; (2) components. Parameters affecting the product may be divided into two groups: (1) controllable; (2) uncontrollable. Controllable parameters can further be divided into three groups with respect to their effects: (1) control parameters; (2) adjustment parameters; (3) ineffective parameters.

The objective is to select the best combination of control parameters so that the process is most robust with respect to noise factors [56]. The Taguchi method utilizes orthogonal arrays from design of experiments theory to study a large number of variables with a small number of experiments. Using orthogonal arrays significantly reduces the number of experimental configurations to be studied.
Furthermore, the conclusions drawn from small scale experiments are valid over the entire experimental region spanned by the control factors and their settings [51-56].

In this study, the parameters are considered for the studied bituminous concrete in Table 1 .

The variation levels for the considered parameters are shown in Table 1.

According to the parameters in Table 1 and their variation levels, orthogonal array is derived.

L16 $\left(2^{15}\right)$ Taguchi's table is used in this study [54]. The mix proportions and temperature are defined as shown in Table 2.

\subsection{Stiffness Modulus Model}

In this study, interactions between parameters are not considered. The interaction between parameters has low impact on the stiffness modulus and has complicated the model without significant contribution [48].

Table 1 Selected factors and levels.

\begin{tabular}{lll}
\hline Parameter & Type & Levels \\
\hline Binder content & Quantitative & 4 \\
Percent of additive & Quantitative & 4 \\
Temperature & Quantitative & 2 \\
\hline
\end{tabular}

Table 2 Details of trials.

\begin{tabular}{llll}
\hline $\begin{array}{l}\text { Trial } \\
\text { number }\end{array}$ & Binder content & $\begin{array}{l}\text { Percent of } \\
\text { additive }\end{array}$ & $\begin{array}{l}\text { Temperature } \\
\left({ }^{\circ} \mathrm{C}\right)\end{array}$ \\
\hline 1 & 4.40 & 0.1 & 170 \\
2 & 4.70 & 0.1 & 170 \\
3 & 4.55 & 0.3 & 170 \\
4 & 4.85 & 0.3 & 170 \\
5 & 4.55 & 0.6 & 170 \\
6 & 4.85 & 0.6 & 170 \\
7 & 4.40 & 0.9 & 170 \\
8 & 4.70 & 0.9 & 170 \\
9 & 4.55 & 0.1 & 200 \\
10 & 4.85 & 0.1 & 200 \\
11 & 4.40 & 0.3 & 200 \\
12 & 4.70 & 0.3 & 200 \\
13 & 4.40 & 0.6 & 200 \\
14 & 4.70 & 0.6 & 200 \\
15 & 4.55 & 0.9 & 200 \\
16 & 4.85 & 0.9 & 200 \\
\hline
\end{tabular}


Performing NAT trials allowed bituminous concrete rigidity to be determined, so the stiffness modulus can be written as:

$$
Y=a_{0}+a_{1} x_{1}+a_{2} x_{2}+a_{3} x_{3}
$$

where, $Y$ is the stiffness modulus of the modified bituminous concrete, $x_{1}$ is the temperature value, $x_{2}$ is the percentage of the binder content, $x_{3}$ is the percentage of the additive and $a_{0}, a_{1}, a_{2}$ and $a_{3}$ are the coefficients to be determined. These ones are obtained by the least square method. The terms of superior order are neglected because of their low effect and the parameter variation is small.

\section{Materials}

\subsection{Bitumen}

40/50 penetration grade bitumen was obtained from NAFTEC Company and used throughout the study. Properties of this bitumen are listed in Table 3.

\subsection{Aggregates}

Crushed aggregates were supplied from Keddara quarry of Boumerdes/Algeria and used in this study. Fig. 2 shows the specification limits of aggregates. Tables 4 and 5 summarize their main characteristics.

Table 3 Properties of the bitumen.

\begin{tabular}{lll}
\hline Property & Value & Specification \\
\hline Penetration $25{ }^{\circ} \mathrm{C}, 1 / 10 \mathrm{~mm}$ & 44 & $35-50$ \\
Softening point $\left({ }^{\circ} \mathrm{C}\right)$ & 52 & $50-58$ \\
Specific gravity $\left(\mathrm{g} / \mathrm{cm}^{3}\right)$ & 1.02 & $1.0-1.05$ \\
Ductility $(\mathrm{cm})$ & $>100$ & $>100$ \\
\hline
\end{tabular}

Ductility $(\mathrm{cm})$

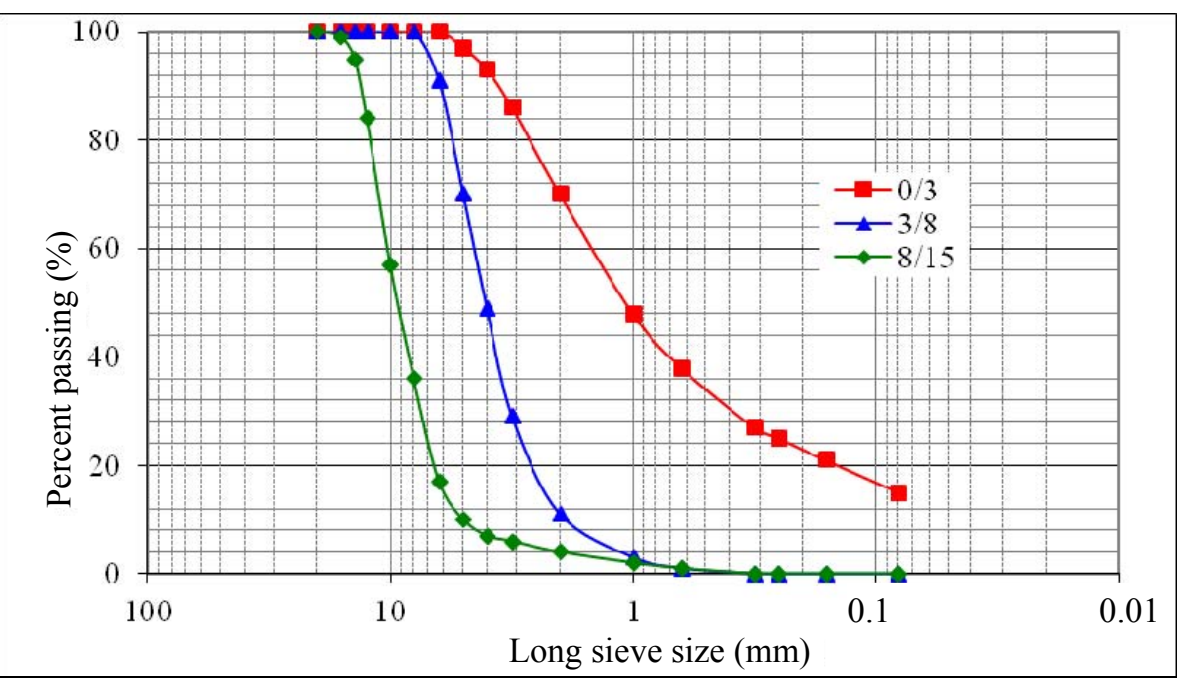

Fig. 2 Aggregates grading curves.

Table 4 Physical characteristics.

\begin{tabular}{lllll}
\hline Aggregate & Sand $(0 / 3)$ & Gravel $(3 / 8)$ & Gravel $(8 / 15)$ & Specification \\
\hline Specific gravity $\left(\mathrm{t} / \mathrm{m}^{3}\right)$ & 2.70 & 2.70 & 2.67 & - \\
Los Angeles abrasion test $(\%)$ & - & 22.01 & 23.84 & $\leq 25$ \\
Micro Deval test (\%) & - & 8 & 15.40 & $\leq 25$ \\
Sand equivalent at $10 \%$ & 64.5 & - & - & $\geq 60$ \\
Flakiness index (\%) & - & 12.65 & 11.47 & $\leq 25$ \\
Cleaning of coarse aggregate & - & 6.78 & 7 & $<2$ \\
Blue methylene value & 1.25 & - & - & $<2$ \\
\hline
\end{tabular}


Table 5 Chemical characteristics in percent.

\begin{tabular}{lll}
\hline Aggregate & Sand $(0 / 3)$ & Gravel $(3 / 8$ and 8/15) \\
\hline Insoluble $\left(\mathrm{SiO}_{2}+\right.$ silicates $)$ & 4.37 & 4.37 \\
$\mathrm{Fe}_{2} \mathrm{O}_{3}+\mathrm{Al}_{2} \mathrm{O}_{3}$ & 1.32 & 1.32 \\
$\mathrm{CaSO}_{4}+2 \mathrm{H}_{2} \mathrm{O}$ & Traces & Traces \\
$\mathrm{NaCl}$ & 0.17 & 0.17 \\
$\mathrm{CaCO}_{3}$ & 94.01 & 94.01 \\
$\mathrm{CO}_{2}$ & 41.36 & 41.36 \\
Iron loss & 41.63 & 41.63 \\
Boiler feed water & 0.27 & 0.27 \\
Organic material & None & None \\
\hline
\end{tabular}

\subsection{Additive}

The PR PLAST Sahara is a plastomer. It is provided in the form of granules varying from 0 to $2 \mathrm{~mm}$. It is used to manufacture wearing course and binder course of hot mix asphalts in desert areas or in hot climate regions. Its anti-shrinkage blended with bitumen allows formulating mixtures resistance to rutting and surface anti cracking in hot climate. Its processing temperature ranges between at least $160{ }^{\circ} \mathrm{C}$ and $170{ }^{\circ} \mathrm{C}$ and its gravity varies from 0.910 to 0.965 . The recommended additive content ranges between $0.2 \%$ and $0.6 \%$ by weight of aggregates.

\section{Test Methods and Results}

Aggregates play an important role in the mechanical performance of the mix. For this reason, the grain size skeleton was mostly composed of $8 / 15$ $\mathrm{mm}(40 \%$ of the total) and $3 / 8$ (15\% of the total) coarse aggregate to provide the mix with bearing capacity. The remaining was composed of $0 / 3$ fraction fine aggregate ( $45 \%$ of the total). The grading curve of the bitumen concrete used in this study is given in Fig. 3.

\subsection{Samples Preparation}

HMAC (hot mix asphalt concrete) is produced by heating the asphalt and aggregates. Then the additive is incorporated. The binder content, the additive and the temperature used are given in Table 2. In this investigation, the hot mixtures asphalts were characterised through Marshall tests. The dimensions of the cylindrical specimens are $101.6 \mathrm{~mm}$ diameter by $63.5 \mathrm{~mm}$ height. The specimens were compacted by applying 75 blows on each side of the specimen in accordance with ASTM D 1559 then stored at ambient temperature for one day. Before performing Marshall tests, the compactness is measured. Then, the standard specimens were immersed in water at $60{ }^{\circ} \mathrm{C}$ for 30 min and then loaded to failure at a constant rate of compression of $0.850 \mathrm{~mm} / \mathrm{s}$ (Table 6).

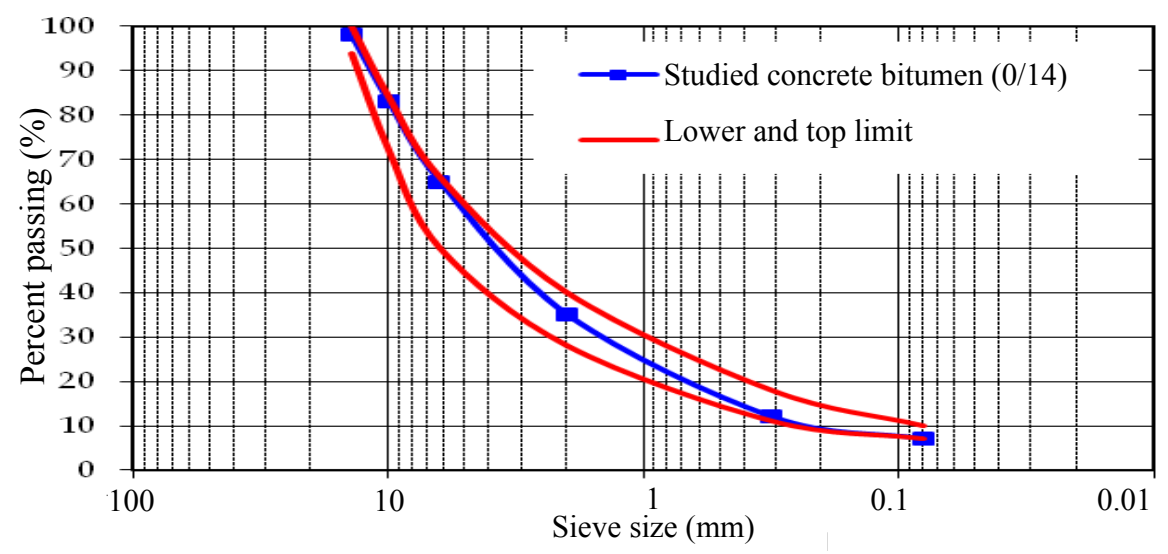

Fig. 3 Mix grading curves. 
Table 6 Mix characteristics.

\begin{tabular}{lrrrr}
\hline Binder content (\%) & 4.85 & 4.70 & 4.55 & 4.40 \\
\hline Compactness & 98.53 & 98.29 & 97.82 & 97.47 \\
\hline
\end{tabular}

Each test is repeated at least three times.

The compactness decreases by decreasing the binder content.

\subsection{Marshall Stability and Flow Test}

The Marshall stability value corresponds to the maximum force recorded during test while the flow is the deformation noted at the maximum force. They are given in Table 7.

The best result corresponds to trial number 11 .

The six best results were chosen in order to perform the measure of the stiffness modulus.

\subsection{NAT (Nottingham Asphalt Tester)}

The Nottingham asphalt tester in Fig. 4 allows measuring the elastic modulus of a bitumen concrete. This indirect tensile test is often used in laboratory characterization of bituminous mixtures. It gives the stiffness modulus with good accuracy for a wide range of test methods and sample sizes, when sinusoidal cyclic tests are considered. Nevertheless, it is a delicate measurement and some conditions should be respected [1]. In order to deal with these conditions, the test consists of performing five test pulses at a frequency of $10 \mathrm{~Hz}$, a temperature of $15{ }^{\circ} \mathrm{C}$ and a commonly used Poisson's ratio of 0.35 (defined by EN 12697-26:2004). The elastic modulus is measured at each pulsation. The obtained modulus is the average of the five values. Each test is done for at least three samples. The results are summarized in Table 8 .

\subsection{Mathematical Model}

Applying Eq. (8), the following system is written:

$$
\left\{\begin{array}{l}
E_{1} \\
E_{2} \\
E_{3} \\
E_{4} \\
E_{5} \\
E_{6}
\end{array}\right\}=\left[\begin{array}{cccc}
1 & T_{1} & C_{1} & A_{1} \\
1 & T_{1} & C_{1} & A_{1} \\
1 & T_{1} & C_{1} & A_{1} \\
1 & T_{1} & C_{1} & A_{1} \\
1 & T_{1} & C_{1} & A_{1} \\
1 & T_{1} & C_{1} & A_{1}
\end{array}\right] \cdot\left\{\begin{array}{l}
a_{0} \\
a_{1} \\
a_{2} \\
a_{3}
\end{array}\right\}
$$

Table 7 Marshall results.

\begin{tabular}{llcl}
\hline Trial & $\begin{array}{l}\text { Percent of } \\
\text { additive }\end{array}$ & Marshall stability $(\mathrm{kN})$ & Flow $(\mathrm{mm})$ \\
\hline 1 & 0.1 & 900 & 3.5 \\
2 & 0.1 & 1,000 & 3.0 \\
3 & 0.3 & 1,250 & 2.6 \\
4 & 0.3 & 1,200 & 2.7 \\
5 & 0.6 & 1,100 & 3.1 \\
6 & 0.6 & 1,050 & 3.1 \\
7 & 0.9 & 1,000 & 3.2 \\
8 & 0.9 & 950 & 3.4 \\
9 & 0.1 & 1,350 & 2.0 \\
10 & 0.1 & 1,250 & 2.1 \\
11 & 0.3 & 1,550 & 1.9 \\
12 & 0.3 & 1,500 & 2.0 \\
13 & 0.6 & 1,100 & 2.8 \\
14 & 0.6 & 1,150 & 2.7 \\
15 & 0.9 & 950 & 3.6 \\
16 & 0.9 & 900 & 3.8 \\
\hline
\end{tabular}

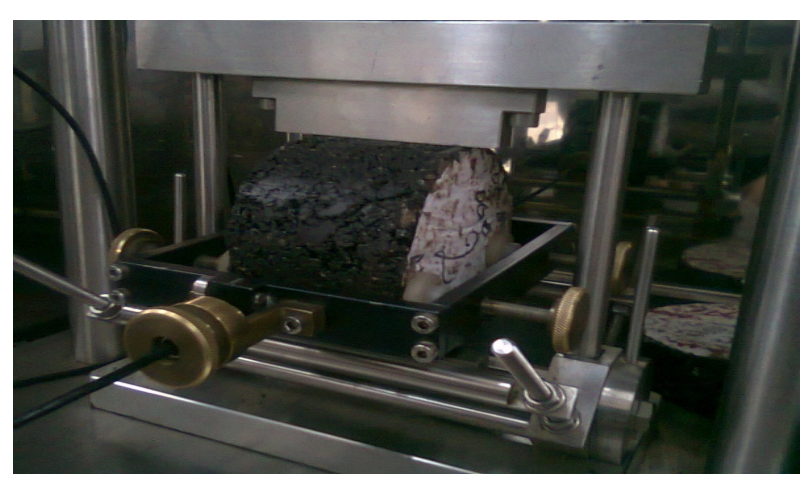

Fig. 4 NAT test.

Table 8 NAT results.

\begin{tabular}{lll}
\hline Trial & $\begin{array}{l}\text { Stiffness modulus of } \\
\text { each sample (MPa) }\end{array}$ & $\begin{array}{l}\text { Average stiffness } \\
\text { modulus (MPa) }\end{array}$ \\
\hline 3 & $12,492,12,000,13,236$ & $\mathrm{E}_{1}=12,576$ \\
4 & $12,312,12,100,12,629$ & $E_{2}=12,347$ \\
9 & $12,622,12,515,13,032$ & $E_{3}=12,723$ \\
10 & $12,440,12,306,13,000$ & $E_{4}=12,582$ \\
11 & $13,587,13,228,16,208$ & $E_{5}=14,341$ \\
12 & $13,367,13,536,15,601$ & $E_{6}=14,168$ \\
\hline
\end{tabular}

i.e.,

$$
\left\{\begin{array}{l}
12,576 \\
12,347 \\
12,723 \\
12,582 \\
14,341 \\
14,168
\end{array}\right\}=\left[\begin{array}{llll}
1 & 170 & 4.55 & 0.3 \\
1 & 170 & 4.85 & 0.3 \\
1 & 200 & 4.55 & 0.1 \\
1 & 200 & 4.85 & 0.1 \\
1 & 200 & 4.40 & 0.3 \\
1 & 200 & 4.70 & 0.3
\end{array}\right] \cdot\left\{\begin{array}{l}
a_{0} \\
a_{1} \\
a_{2} \\
a_{3}
\end{array}\right\}
$$


Table 9 Validation range.

\begin{tabular}{ll}
\hline Parameter & Range \\
\hline Binder content & $4.40 \%-4.85 \%$ \\
Percent of additive & $0.1 \%-0.4 \%$ \\
Temperature & $170{ }^{\circ} \mathrm{C}-200{ }^{\circ} \mathrm{C}$ \\
\hline
\end{tabular}

A resolution by the least square method leads to derived Eq. (9) as:

$$
E=3,382.42+56.75 \mathrm{~T}-603.33 C+7,557.50 A(12)
$$

where, $T$ is the temperature, $C$ is the percentage of binder contains, $A$ is the percentage of additive and $E$ is the stiffness modulus.

The uncertainty on this modulus can be stated:

$$
\Delta E / E=\Delta C / C+\Delta T / T+\Delta A / A
$$

For the best result of $E$, the uncertainty is:

$$
\Delta E / E=2.6 \%
$$

so Eq. (12) can be written in the following form:

$$
\begin{gathered}
E=3,382.42+56.75 \mathrm{~T}-603.33 C \\
+7,557.50 A \pm 370 \mathrm{MPa}
\end{gathered}
$$

Typically, a stiffness model should include temperature, loading frequency, aggregate grading characteristics, binder type and mixture volumetric characteristics as factors. Some of them are considered in the given model. An investigation could be conducted in order to develop another model taking into account all these factors but this will increase the number of tests and the cost. Nevertheless, the developed model gives an accurate stiffness modulus with less effort and can be used as a basis to develop a more accurate predictive model.

\section{Conclusions}

A bituminous concrete modified by the new additive, PR PLAST Sahara, has been investigated and the following conclusions have been drawn:

(1) The use of Taguchi method in experimental design allowed the authors to perform 16 tests instead of the original 32 . This allows them to gain time and reduce costs;

(2) The optimum conditions determined by the method in a laboratory environment are reproducible in situ;
(3) Marshall stability has been improved by PR PLAST Sahara modification which would be worthwhile for the bituminous mixtures to resist permanent deformations such as rutting;

(4) The optimum conditions are additive content of $0.3 \%$, binder content of $4.40 \%$ and a temperature of $200{ }^{\circ} \mathrm{C}$;

(5) The stiffness modulus has been improved by the addition of the PR PLAST Sahara and a mathematical model has been developed;

(6) This model can be used for studying the influence of the different parameters;

(7) The proposed model is valid in the ranges given in Table 9;

(8) The PR PLAST Sahara greatly improves the mixed asphalt's resistance to rutting and modulus of elasticity of the bituminous mix.

Consequently, PR PLAST Sahara will provide additional resistance for roadways to resist pavement distresses. PR PLAST Sahara modified concrete bitumen is recommended to use in hot climate regions, in expressways, in roadways with heavy vehicle traffic, at bus stations, at horizontal curved sections and at roadway junctions. This is of a high interest for professional contributors in building highways in hot climate region (Middle East and African countries).

\section{References}

[1] H.D. Benedetto, M.N. Partl, L. Francken, C.D.L. Roche Saint André, Stiffness testing for bituminous mixtures, Materials and Structures 34 (2001) 66-70.

[2] J. Neves, A.G. Correia, Evaluation of the stiffness modulus of bituminous mixtures using laboratory tests (NAT) validate by field back-analysis, in: 7th International Conference on the Bearing Capacity of Roads, Railways and Airfields (BCRA'05), Trondheim, Norway, June 27-29, 2005.

[3] S.M. Abtahi, M. Sheikhzadeh, S.M. Hejazi, Fiber-reinforced asphalt-concrete, a review, Construction and Building Materials 24 (2010) 871-877.

[4] R.L. Terrel, S. Al-Swailmi, Water Sensitivity of Asphalt-Aggregate Mixes: Test Selection, SHRP report A-403, Strategic Highway Research Program, National Research Council, 1994.

[5] E. Sanchez-Alonso, A. Vega-Zamanillo, D. 


\section{Laboratory Evaluation of the Stiffness Modulus of a Modified Bituminous Concrete with PR PLAST Sahara}

Castro-Fresno, M. DelRio-Prat, Evaluation of compactability and mechanical properties of bituminous mixes with warm additives, Construction and Building Materials 25 (2011) 2304-2311.

[6] M.C.C. Lucena, S.A. Soares, J.B. Soares, Characterization and thermal behavior of polymer-modified asphalt, Material Research 7 (4) (2004) 529-534.

[7] P. Radziszewski, Modified asphalt mixtures resistance to permanent deformations, Journal of Civil Engineering and Management 13 (4) (2007) 307-315.

[8] U. Isacsson, X. Lu, Testing and appraisal of polymer modified road bitumens - State of the art, Mater Struct. 28 (1995) 139-159.

[9] M.S. Cortizo, D.O. Larsen, H. Bianchetto, J.L. Alessandrini, Effect of the thermal degradation of SBS copolymers during the ageing of modified asphalts, Polym Degrad Stab. 86 (2) (2004) 275-282.

[10] B. Sengoz, G. Is1kyakar, Analysis of styrene-butadiene-styrene polymer modified bitumen using fluorescent microscopy and conventional test methods, J. Hazard. Mater. 150 (2008) 424-432.

[11] S. Tayfur, H. Ozen, A. Aksoy, Investigation of rutting performance of asphalt mixtures containing polymer modifiers, Construction and Building Materials 21 (2007) 328-337.

[12] Z. Vlachovicova, C. Wkumbura, J. Stastana, L. Zanzotto, Creep characteristics of asphalt modified by radial styrene-butadiene-styrene copolymer, Constr. Build Mater. 21 (2007) 567-577.

[13] B.V. Kok, M. Y1lmaz, The effects of using lime and styrene-butadiene-styrene on moisture sensitivity resistance of hot mix asphalt, Constr. Build Mater. 23 (2009) 1999-2006.

[14] S.S. Galooyak, B. Dabir, A.E. Nazarbeygi, A. Moeini, Rheological properties and storage stability of bitumen/SBS/montmorillonite composites, Constr. Build Mater. 24 (2010) 300-307.

[15] G.D. Airey, Rheological properties of styrene-butadiene-styrene polymer modified road bitumens, Fuel 82 (2003) 1709-1719.

[16] A.I. Al-Hadidy, Y. Tan, T.H. Ayman, Starch as a modifier for asphalt paving materials, Constr. Build Mater. 25 (2011) 14-20.

[17] S. Gupta, A. Veeraragavan, Fatigue behaviour of polymer modified bituminous concrete mixtures, Journal of the Indian Roads Congress (1-3) (2009) 548 .

[18] U. Isacsson, H.Y. Zeng, Relationships between bitumen chemistry and low temperature behavior of asphalt, Constr Build Mater. 11 (2) (1997) 83-91.

[19] P. Ahmedzade, M. Tigdemir, S.F. Kalyoncuoglu, Laboratory investigation of the properties of asphalt concrete mixtures modified with TOP-SBS, Construction and Building Materials 21 (2007) 626-633.

[20] Y. Yildirim, Polymer modified asphalt binders, Construction and Building Materials 21 (2007) 66-72.

[21] S. Shuler, I. Douglas, Improving durability of open-graded friction courses, Transport Res. Rec. 1259 (1990) 35-41.

[22] M.C. Won, M.K. Ho, Effect of antistrip additives on the properties of polymermodified asphalt binders and mixtures, Transport Res. Rec. 1436 (1994) 108-114.

[23] C. Gorkem, B. Sengoz, Predicting stripping and moisture induced damage of asphalt concrete prepared with polymer modified bitumen and hydrated lime, Construction and Building Materials 23 (2009) 2227-2236

[24] S. Haddadi, E. Ghorbel, N. Laradi, Effects of the manufacturing process on the performances of the bituminous binders modified with EVA, Construction and Building Materials 22 (2008) 1212-1219.

[25] H. Behbahani, H. Ziari, S. Noubakhat, The use of polymer modification of bitumen for durant hot asphalt mixtures, Journal of Applied Sciences Research 4 (1) (2008) 96-102

[26] H. Chen, Q. Xu, Experimental study of fibers in stabilizing and reinforcing asphalt binder, in: 17th International Symposium on Alcohol Fuels, Taiyuan, China, 2010, pp. 1616-1622.

[27] X.M. Liu, S.P. Wu, Study on the graphite and carbon fiber modified asphalt concrete, Construction and Building Materials 25 (2011) 1807-1811.

[28] S.G. Jahromi, A. Khodaii, Carbon fiber reinforced asphalt concrete, The Arabian Journal for Science and Engineering, 2008, B2.

[29] A.Z. Shahabadi, A. Shokuhfar, S.E. Nejad, Preparation and rheological characterization of asphalt binders reinforced with layered silicate nanoparticles, Constr. Build Mater. 24 (2010) 1239-1244.

[30] S.G. Jahromi, B. Andalibizade, S. Vossough, Engineering properties of nanoclay modified asphalt concrete mixtures, The Arabian Journal for Science and Engineering, 2010, B1.

[31] J. Yu, X. Zeng, S. Wu, L. Wang, G. Liu, Preparation and properties of montmorillonite modified asphalts, Mat Sci Eng A-Struct. 447 (2007) 233-238.

[32] D. Arslan, M. Guru, M.K. Cubuk, M. Cubuk, Improvement of bitumen and bituminous mixtures performances by triethylene glycol based synthetic polyboron, Construction and Building Materials 25 (2011) 3863-3868.

[33] N.Z. Habib, I. Kamaruddin, M. Napiah, I.M. Tan, Effect of mixing process on polypropylene modified bituminous concrete mix properties, in: International Conference on 
Civil and Environmental Engineering ICCEE 2011, Bali, Indonesia, Oct. 26-28, 2011.

[34] S. Hinislioglu, H.N. Aras, O.U. Bayrak, Effects of high density polyethylene on the permanent deformation of asphalt concrete Indian, Journal of Engineering and Material Sciences 12 (2005) 456-460.

[35] S.T.A. Khan, S.D.K. Sharma, Effect of waste polymer modifier on the properties of bituminous concrete mixes, Construction and Building Materials 25 (2011) 3841-3848.

[36] S.T.A. Khan, S.D.K. Sharma, B.M. Sharma, Performance evaluation of waste plastic/polymer modified bituminous concrete mixes, Journal of Scientific and Industrial Research 68 (2009) 975-979.

[37] O.N. Celik, C.D. Atis, Compactibility of hot bituminous mixtures made with crumb rubber-modified binders, Construction and Building Materials 22 (2008) 1143-1147.

[38] F. Moreno, M.C. Rubio, M.J. Martinez-Echevarria, The mechanical performance of dry-process crumb rubber modified hot bituminous mixes: The influence of digestion time and crumb rubber percentage, Construction and Building Materials 26 (2012) 466-474.

[39] F. Moreno, M.C. Rubio, M.J. Martinez-Echevarria, Analysis of digestion time and the crumb rubber percentage in dry-process crumb rubber modified hot bituminous mixes, Construction and Building Materials 25 (2011) 2323-2334.

[40] S.A. Tekalur, A. Shukla, M. Sadd, K.W. Lee, Mechanical characterization of a bituminous mix under quasi-static and high-strain rate loading, Construction and Building Materials 23 (2009) 1795-1802.

[41] S. Hinishoglu, E. Aglu, Use of waste high density polyethylene as bitumen modifier in asphalt concrete mix, Materials Letters 58 (2004) 267-271.

[42] S. Kongsuwan, S. Phetcharat, Rubber asphalt composition and application in road pavement, in: Fourth Regional Symposium on Infrastructure Development in Civil Engineering (RSID4), Bangkok, Thailand, 2003.

[43] M.N. Borhan, F. Suja, A. Ismil, R.A.O.K. Rahmat, Used cylinder oil modified col-mix asphalt concrete, Journal of Applied Sciences 7 (22) (2007) 3485-3491.

[44] D.D. Carlson, H. Zhu, Asphalt-rubber an anchor to crumb rubber markets, in: Third Joint UNCTAD/IRSG
Workshop on Rubber and the Environment International Rubber Forum, Veracruz, Mexico, 1999.

[45] P. Bandini, Rubberized Asphalt Concrete, Pavements in New Mexico Market Feasibility and Performance Assessment, Department of Civil Engineering, New Mexico State University, Mexico, 2011.

[46] N.I.M. Yusoff, M.T. Shaw, G.D. Airey, Modelling the linear viscoelastic rheological properties of bituminous binders, Construction and Building Materials 25 (2011) 2171-2189.

[47] S. Zhi, W.W. Gun, L.X. Hui, T. Bo, Evaluation of fatigue crack behavior in asphalt concrete pavements with different polymer modifiers, Construction and Building Materials 27 (2012) 117-125.

[48] I. Harizi, Improved stiffness modulus of asphalt by the addition of an additive, Master Thesis, University Saad Dahlab, Blida, Algeria, 2012.

[49] A. Tabakovic, A. Karac, A. Ivankovic, A. Gibney, C. McNally, M.D. Gilchrist, Modelling the quasi-static behaviour of bituminous material using a cohesive zone model, Engineering Fracture Mechanics 77 (2010) 2403-2418.

[50] F.K.M. Hamed, Evaluation of fatigue resistance for modified asphalt concrete mixtures based on dissipated energy concept, Ph.D. Thesis, Department of Civil Engineering and Geodesy, Darmstadt, 2010.

[51] B. Maskri, Intelligent computation structures object oriented approach, Magister Thesis, University Saad Dahlab, Blida, Algeria, 2006. (in French)

[52] B. Soulier, On experimental mechanics modeling: Precision, optimization and industrial applications, Dr. Thesis, Ecole Normale Supérieure de Cachan, France, 1994. (in French)

[53] G.N. Vanderplaats, Numerical Optimazation Techniques for Engineering Design, 3rd ed., Vanderplaats Research and Development, University of Michigan, 1999, p. 333.

[54] G. Taguchi, System of Experimental Design, Unipub, White Plains, New York, 1987.

[55] S.M. Phadke, Quality Engineering Using Robust Design, Prentice Hall, New Jersey, 1989.

[56] A. Tortum, C. Celik, A.C. Aydin, Determination of the optimum conditions for tire rubber in asphalt concrete, Building and Environment 4 (2005) 492-1504. 